\title{
O ser e o fazer-se professor: Ressignificando valores, tecendo a teia da vida
}

\author{
Maria Dolores Fortes Alves, Pontificia Universidade Católica, São \\ Paulo, Brazil
}

\begin{abstract}
Resumen: Em tempos de incertezas, de verdades fractais, a educação, bem como, os Educadores encontram-se sem nortes sobre o que ensinar, para quem ensinar, a favor de quem e contra quem. Por isso, temos como objetivo neste artigo, refletir sobre o porquê e para que ensinamos e aprendemos. Discorreremos sobre a importância dos valores na práxis pedagógicas bem como, sua relevância na tessitura da teia da vida. Assim, versaremos sobre o "ser e o fazer do Educador". Esta reflexão farse-á a luz do Pensamento Complexo, da Transdisciplinaridade e do Pensamento Ecossistêmico. Uma trajetória reflexiva que possibilitar-nos-á perceber que muito mais que formar indivíduos tecnicamente capazes de atuar na sociedade. Precisamos de uma educação que nos legitime enquanto sujeitos únicos, singulares, e partes do Todo. Ao educador e a educação outorga-se prioritariamente semear a humanização pela humana-ação.
\end{abstract}

Palabras Clave: Formação de Professores, Diversidade, Novos Paradigmas

Abstract: In times of uncertainty, fractal truths, education as well as Educators has no north on what to teach, whom to teach, to whom and against whom. By this reason we aim in this article to reflect on why and what to teach and learn. Will discuss the importance of values in educational praxis as well as its relevance in the construction of the web of life. This way we excercise "Educator being and doing." This reflection will light the Complex Thought and the Transdisciplinarity Ecosystem thoughts. A reflective journey that enable us to realize that rather than being technically able to train individuals to act in society. We need an education that legitimizes us as unique person, singular, and parts of the whole. To educator and education grants to sow humanization primarily by human action.

Keywords: Teacher Formation, Diversity, New Paradigms

\section{Introducción}

"Educar deveria ser como amar.. reconhecer o outro como legítimo outro.

Reconhecê-lo e legitimá-lo em sua totalidade..."

(Maria Dolores Fortes Alves)

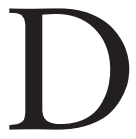

ISCORRER AQUI SOBRE as ameaças planetárias e a vida se faz desnecessário. Cabe-nos neste texto refletir sobre o Ser e o Fazer do Educador. E, a esta reflexão compete-nos algumas questões norteadoras: Professor, o que te guia? O que te projeta adiante? Quais são teus valores e teus amores? Que mundo queremos para nossos alunos e filhos e que alunos e filhos queremos para o mundo? Ensinar o quê, para quê, a favor de quem contra quem? Estas últimas questões nos apresentou com tanta ênfase e frequência, nosso querido educador Paulo Freire.

Revista Internacional de Educaci ón y Aprendizaje

Volumen 1, 2013, http://sobrelaeducacion.com/revistas/coleccion/, ISSN 2255-453X

(C) Global Knowledge Academics. Maria Dolores Fortes Alves

Todos los Derechos Reservados. Permisos: soporte@gkacademics.com

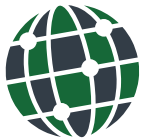


Estamos em tempos de incertezas, conhecimentos e verdades transitórias em todas as áreas, inclusive na família na sociedade e na Educação. Como consequência da modernidade liquida como no ensina Bauman (2001), e, como consequência, temos também sentimentos líquidos. Os laços se afrouxam e os sentimentos apresentam-se com liquidez e podemos dizer que, como liquidação. Amores baratos. Em uma sociedade capitalista, sujeitos e sentimentos se transformam em mercadoria. Perdeu-se o doce sabor e a alegria da partilha generosa, de vínculos sábios e sadios. Nossa sociedade trabalha e se desenvolve, melhor expondo, se des-envolve, pois perdemos o envolvimento, nossos elos de ligação. Como sequela destes tempos de não envolvimento, de liquidez de sentimentos e valores, temos aquilo que chamado de bullying- que, percebido por Alves (2011), como sintoma da patologização do sistema capitalista.

Confirma isto que foi dito, o filósofo Edgar Morin (2002), mas também acrescenta que, podemos não ter nenhuma certeza, mas devemos ter sim, alguns princípios e valores eis a nossa esperança: o renascer e o ressignificar de valores. E sobre isto e novos caminhos para o Ser e fazer-se Educador, que falaremos neste artigo.

\section{Quando nada se faz certo, tudo se faz possível}

Situamo-nos no início da segunda década do século XXI e em muito a ciência e a tecnologia evoluiu. Encontramo-nos em tempos de incertezas, conhecimentos e verdades transitórias em todas as áreas.

Século passado, antes da década de 60, dizer que poderíamos falar e ver nossos amigos e parentes em outro hemisfério parecia-nos algo utópico, alguns zombariam. Hoje, não só vemos e ouvimos outro e outros, em um longínquo hemisfério, através de computadores e celulares, como nos conectamos em segundos e desenvolvemos tecnologias e parcerias com pessoas a milhas de distância de nós. O conhecimento se expande, tornou-se incontrolável, bem como, imensurável em poder de criação e transmissão.

Ensinamos e aprendemos de diversas maneiras e por diversos modos, com diversos recursos. Para suprir as dificuldades de aprendizagem temos serviços e equipamentos de tecnologia assistiva que hoje vão desde sintetizadores de voz a equipamentos que decodificam o piscar dos olhos, ou mesmo o simples torcer de nariz, e interpretam estes sinais transcrevendo-os em palavras, frases, livros; ligam outros equipamentos, acendem e apagam luzes, etc. Contudo, não se inventou nenhum equipamento mais avançado que o acolhimento e a amorosidade para ensinar o humano a ser humano ou mesmo para termos a sensibilidade de identificar qual é a melhor maneira de acessar o mundo interno de outro humano e ajudarlhe a desenvolver seu potencial de autoria.

Podemos ensinar ou aprender quase tudo, desde que queiramos e tenhamos as ferramentas (internas e externas) assim como, as informações disponíveis. Ferramentas e informações externas se têm, às vezes até em excesso. E para este excesso é necessário ter-se um mediador para ajudar-nos na escolha e no colher de informações para transformá-las em conhecimentos.

O grande problema hoje é identificar quais são os conhecimentos pertinentes (Morin, 1996), quais são os saberes que são e serão adequados a cada situação, contexto e momentos. Necessitamos ter discernimento para identificar nossas cegueiras trazidas pelo conhecimento que se fez verdade. Precisamos lembrar que as verdades são transitórias e dependem de um contexto e momentos históricos. 
As razões do para quê e do porquê reconhecer nossas cegueiras e identificar os conhecimentos pertinentes se explicam nos "Sete saberes necessários para o presente e futuro" de Edgar Morin (1996). Entre estes saberes está também "Ensinar a condição humana; Ensinar a identidade terrena; Ensinar a compreensão; A ética do gênero humano". São os saberes descritos por Morin e propagados pela UNESCO como bases para a Educação do Futuro. Poderíamos dizer também que estes saberes se fazem necessários "para que tenhamos futuro". Para que possamos proteger a Vida e o planeta Terra. Acreditamos que, hoje mais que antes, temos acima de tudo, que ensinar para que tenhamos futuro... para que tenhamos vida. Para que a vida, todas as formas de vida sejam protegidas. Das outras coisas não temos nenhuma certeza, mas destas temos sim, desde que tenhamos alguns princípios e valores... desde que queiramos ter mais homens do que bombas...

"Não temos nenhuma certeza, nenhuma prova irrefutável de que haverá progresso, não temos nenhuma promessa, mas temos, apesar de tudo, finalidades e valores. Nós podemos apostar neles. E nutrir uma esperança. Uma esperança do improvável. [...] Esperar o improvável, apostar e trabalhar na direção de nossas finalidades e de nossos valores é mais reconfortante do que se curvar diante do fato consumado e apenas sobreviver". (Morin, 2002, p. 37)

\section{Conversar. Com-versar, versar com o outro. Sobre o ser e o fazer do professor-educador}

Lembramos que na escola formal, ensinamos para traduzir, repartir, construir, transmitir, divulgar os conteúdos culturalmente construídos, mas, talvez mais que isto. Como nos ensina o antropólogo e Educador brasileiro, contemporâneo de Paulo Freire, Carlos Rodrigues Brandão (2005), devemos também ensinar para que os conhecimentos culturalmente construídos favoreçam que os sujeitos encontrem o caminho que os conduzem, essencialmente, ao alargar da capacidade de se voltar para o amor a si mesmo, ao outro, ao mistério da vida que comparto com outros (humanos e não humanos). O aprender e o ensinar devem servir para reencontrar o percurso que nos leva a nós mesmos e o outro a si mesmo. Portanto, os processos de ensino e aprendizagem necessitam promover significados, sentidos ao objeto de conhecimento, e ainda, serem acessíveis a todas as pessoas.

Nota-se igualmente, como tantas vezes nos alertou Freire $(1985,2001)$, que o conhecimento, bem como o ensinar, fazem-se carregado de intencionalidade, quer o professor tenha consciência disto ou não. Sempre estamos ensinando a favor de alguma situação ou de alguém, contra alguma situação ou alguém. Ou seja, toda nossa práxis vem revestida de valores. E, nestes valores, nesta intencionalidade consciente ou velada, será favorecido o libertar, a emancipação dos sujeitos ou, a práxis e corporificação destes valores irão perpetrar a opressão e a hierarquia.

Como disse Alves (2009), a Educação não é a salvação de todos os males assim como o Professor não é o salvador da pátria e da humanidade. Contudo, a educação e mesmo o educador configuram-se como protagonistas de importância primordial na formação e na transformação dos valores presentes na sociedade.

Consta em nossa constituição (do Brasil), bem como na carta da UNESCO e em diversos outros documentos, que a paz, a democracia, a justiça, a solidariedade, a generosidade, a dignidade, a cidadania, a igualdade de oportunidades, o respeito às diferenças são alguns 
dos valores almejados pela comunidade planetária. Portanto, devem estar nos objetivos e ações dos membros da comunidade escolar, em busca de sua construção e polinização.

Sabemos que, o que traz sentido ao nosso o viver, está para além do fazer, está na essência do ser... Para significar o viver, existem valores que fazem a diferença: são estes valores sementes da humanidade, valores Humanos essenciais, que cabe ao educador, pelo ato de amor, fazer germinar...

\title{
Sobre formação e trans-formação de professores
}

\author{
"Não se pode falar de educação sem amor" \\ Paulo Freire
}

A entrada no século XXI foi marcada por profundas mudanças no modo de vida do homem ocidental. Pelos caminhos e descobertas da física quântica, da biologia e de outras ciências, demonstrou-se que as ideias cartesianas "das partes", da "razão pura" deixam de serem verdades absolutas para cederem lugar a novos pensamentos. Percebeu-se que o homem, assim como tudo que está na Natureza faz parte de um sistema e de sistemas de sistemas. Em níveis orgânicos ou quânticos, estamos em constante relação. Indivíduo, Sociedade e Natureza formam uma imensa rede de conexões (rizona) com suas relações retroativas e/ou recursivas.

Concordo com Alves (2009a, 2009b), quando explica que o processo de educativo não pode mais estar desconectado das recentes cobranças determinadas pela complexidade social, econômica, política, cultural e espiritual. Pois, nesta conjunção as subjetividades se constituem mutuamente na intersubjetividade de relações dialógicas.

Contudo, para percebermos o homem como um sujeito integrado, devemos olhá-lo também a partir de sua relação consigo: sua afetividade, seu egocentrismo, sua subjetividade, de sua intersubjetividade e seu altruísmo. Para tal, também na educação é necessário haver uma mudança de pensamentos e valores para que sejam elaborados novos paradigmas, novas miradas, novos pensamentos. Para isto, a educação deve avançar com urgência além dos paradigmas da "educação bancária". Prontamente, tornou-se imprescindível, o "aprender, a aprender, a fazer, a ser, a conviver", como ensina Delors (2000), trazendo-nos os quatro pilares para a Educação.

A busca do aprender a ser e aprender a conviver são fundantes para que a educação do presente e do futuro seja alicerçada como um compromisso educacional e social de proteção à vida e ao planeta. Para além de serem pilares da educação para o sec. XXI, estas são aprendizagens fundamentais para a sociedade, sendo esta compreendida como princípio básico de cooperação (Maturana, 1997). Nesta expressão, este autor nos alerta que a sociedade e humanidade, somente existem dentro de princípios de cooperação e solidariedade, fora destes princípios, deixa de ser humanidade e sociedade. Ou seja, o humano configura-se biológica e ontologicamente como um ser social que necessita conviver em grupo. Caso contrário, sem cooperação, desintegra-se a sociedade e a vida.

Deste modo, pensar a formação do professor é pensar a formação do humano, pensar em valores, visto que, em sua práxis está implícita a atitude política de transformação ou de manutenção da opressão. Para isto, Feldmann (2009, p. 71) nos expõe:

"Formar professores com qualidade social e compromisso político de transformação tem se mostrado um grande desafio às pessoas que compreendem a educação como 
bem Universal, como espaço público, como um direito humano e social na construção da identidade e exercício da cidadania".

A Formação de professores na contemporaneidade constitui-se nesta perspectiva como uma ação de continuidade e inconclusa, transversalizada pelas manifestações históricas, políticas, sociais, relacionais e contextuais, uma vez que nos encontramos em momentos das incertezas, em um tempos-que ocorre em espaços-saberes fractais. Ainda, este processo perpassa e remete-nos ao refletir sobre valores, concepções e ideologias. Na complexidade desta contextura cabem-nos reflexões a respeito:

- Sobre a gravidade da problemática educacional:

- Sobre as questões tecnológicas, ambientais, ecológicas, éticas e sociais:

- Sobre a complexidade de nossa realidade (MORIN, 2000):

Como possibilidade oferecida a estas reflexões, Moraes (2003, 2004, 2008) nos diz que precisamos acreditar na Reforma do pensamento. Numa transformação da educação, numa trans-formação do Ser e fazer-se Professor-Educador.

Também completa Alves,

"O professor pode ser um funcionário das instituições que gerencia, um especialista em reprodução de conhecimentos e uma peça no aparelho ideológico de estado. Um educador, ao contrário, é um fundador de mundos, mediador de esperanças, pastor de projetos". (Alves apud Alves, 2009a, p. 140)

A teoria do Pensamento Complexo de Edgar Morin (2000b), do Pensar Transdisciplinar, de Basarab Nicolescu (1999) e do Pensamento Eco-sistêmico de Maria Cândida Moraes (2004) assinalam algumas novas possibilidades para esta trajetória de transformação do pensamento e da práxis educacional. Em suas obras, esses autores dizem-nos que precisamos ter consciência e abertura para a multidimensionalidade, para a complexidade (a consciência de que tudo é tecido em conjunto), para a incompletude do saber e do ser para a consciência do para além de fronteiras e disciplinas, para os muitos níveis de realidade.

Destarte, o Educador deve ter consciência que prioritariamente a educação deve ser um processo de humanização. Este se situa no muito além de somente formar indivíduos tecnicamente capazes de atuar na sociedade. Seu papel constitui-se também em um ato de amor, no desejo de despertar os valores universais que nos conduzem à autoria Vida e de pensamento, fazendo-nos renascer como flores que somos no imenso e fraterno jardim da Humanidade Ecológica... (Alves, id).

"Uma sociedade onde caibam todos só será possível num mundo no qual caibam muitos mundos. A educação se confronta com essa apaixonante tarefa: formar seres humanos para os quais a criatividade a ternura sejam necessidades vivenciadas em elementos definidores dos sonhos de felicidade individual e social". (Assmann,1998, p. 29)

Para ensinar conteúdos o professor não precisa necessariamente estar presente na sala de aula, pode até mesmo ensinar à distância. No entanto, para se despertar artistas da vida, parteiros de sonhos e do amor, isto sim, cabe ao Educador (Alves, 2009a). Logo, para se ensinar a conviver, e a ser é necessário que Educadores estejam presentes para que, com o 
abraço e o olhar, possam ao coração aquecer e, ao humano acolher.... Porque o humano somente se faz humano pelo olhar amoroso e acolhedor de outro humano.

Para que o aprender a ser e a conviver se realizem é necessário que no fazer do professor contemple-se estratégias didáticas a co-responsabilidade e cooperação como atitudes básicas que necessitam ser cultivadas nos ambientes educacionais, em todos os níveis e etapas processuais. É necessário que contemplem espaços de cruzamento de diversos saberes, linguagens, culturas, metodologias e representações voltadas para expressão do conhecimento humano, da criatividade e da sustentabilidade constitutiva do Triângulo da Vida (D’Ambrósio, 1997).

Uma vez que, o trabalho docente acontece no contexto das interações humanas, por conseguinte, faz-se na relação com seres humanos, sobre seres humanos e para seres humanos. Isto implica dizer que nenhuma experiência se construirá no vazio, ou seja, a qualidade das relações irá interferir de modo impar na aprendizagem (Tardif; Lessard, 2005).

Aprendemos valores e ensinamos valores em todos os momentos, em todas as situações. Consciente ou inconscientemente, os partilhamos. Entretanto, cabe-nos perguntar: o que são valores e qual sua importância na ação do Professor?

Para Alves:

"Valores como aquelas qualidades características dos objetos, das ações e das instituições atribuídas e preferidas, selecionadas ou elogiadas de maneira livre, consciente, que servem para o indivíduo orientar seus comportamentos e ações. (2009a, p. 24)"

Os valores, no sentido qualitativo e humanista, fazem com que o homem seja como tal, sem o qual se perderia a humanidade ou parte dela. O valor se refere a uma excelência ou uma perfeição. Falar de valores humanos significa conceber o homem como o supremo valor entre todas as coisas e que não supera a nenhum outro valor terreno, dinheiro, estado ou ideologia. Valores, no sentido humanista, colocam o homem em conexão com a natureza, não acima dela. Portanto, falamos do homem enquanto um ser ecossistêmico.

Cabe deixar claro que, abordamos aqui os valores enquanto referenciais de construção de uma Ética da Vida (Boff, 1999). E, como defende este autor e filósofo, hoje não é mais possível falar em ética da vida, sem fazer referência aos nossos valores, sem falar de amor e cuidado, de acolhimento, de compreensão e cooperação.

Os valores significam e significam o nosso caminhar, o nosso mirar adiante e seguir. Estão intrínsecos em nossa subjetividade e perpassam a intersubjetividade de nossa práxis educacional e de vida, influenciando aqueles que conosco, de algum modo interagem. Portanto, falar sobre valores em um sentido humanista significa ter o máximo de respeito-reverência à interdependência humana e entre todas as espécies (ALVES, 2009b). Deste modo, enquanto Educadores, devemos conhecer nossos valores, pois são eles que guiam nossa intencionalidade educativa.

Como diz Maturana e Rezepka (2000, p. 16):

"Não se deve ensinar valores, é preciso vivê-los a partir do viver na biologia do amor. Não se deve ensinar a cooperação, é preciso vivê-la desde o respeito por si mesmo que surge no conviver, no respeito mútuo".

Igualmente acrescenta-nos o Educador sueco Rudolf Steiner: 
"O conhecimento do homem sob o ponto e vista espiritual e sua conexão com o cosmos: a educação dá-se mais pelo que o educador é, do que pelo que ele diz, ou técnica que usa. A criança imita, absorve corporalmente o que vê e sente ao redor, e assim estrutura suas experiências por meio do brincar livre, criativo, que parte da imaginação". (Steiner, 1998)

Ainda, complementa Maturana (1997) falando em seus muitos escritos sobre a biologia do amor e do conhecer, bem como, enfatizando o que dissemos acima: a sociedade somente funda-se como sociedade a partir dos enlaces de cooperação e co-construção. Esta é constituída por humanos que através do conviver e do comunicar, (seja esta comunicação oralizada, escrita, corporal ou em nível energético) constroem a sociedade que os constrói.

Somente como seres antropobiopsicossociais, na cooperação e amorosidade é que exercermos nosso papel na e da tessitura social. Seres conscientes de sua história de cooperação enquanto sujeitos e espécie, de socialidade, biológicos, que podem praticar a ação política com autonomia, com plenitude de direitos e deveres. Do mesmo modo, reconhecer que a coparticipação e interação de sujeitos diversos, com suas potencialidades de superação e resiliência, possibilita a Educação, ao educador, ao educando e a sociedade, mútuo enriquecimento.

Sabemos que os processos de cooperação, de coconstrução, de coevolução também são constituídos por ações ecologizadas que ocorrem a partir de interações mútuas entre diferentes sujeitos, entre sujeitos e objetos, sujeitos e meio. Para Moraes (2004), o conhecimento não é produto de um sujeito que está absolutamente disjunto da natureza ou desligado do contexto, e sim resulta de interações com o mundo e com a realidade a qual os sujeitos pertencem. É resultado de interações com o que acontece no local, a partir de suas conexões com o global.

Tanto no contexto biológico quanto ontológico, os seres humanos insurgiram centrados na conservação de um modo de "conviver amoroso", num contexto de prazer e bem estar, que trazem consigo a sensualidade, a cooperação, a ternura, a sexualidade e o companheirismo (Maturana; Verden-Zoller, 2004). Completando este pensamento, Maturana e Varela (1995), afirmam que educar é um fenômeno com implicações biológicas e ambientais que reverberam em todas as dimensões do humano (mente, corpo, espírito). Ou seja, todas as representações interiores guardadas na memória se explicitam através de conversações, negociações e diálogos que estabelecemos uns com os outros, com a natureza e com o Sagrado (Moraes e Torre, 2004). Igualmente, percebemos que a nossa maneira de ser, de sentir, pensar e agir, nossos valores, hábitos, atitudes e demais representações internas que permeiam as nossas relações com a realidade, refletem a visão que temos do mundo.

Isso nos sugere que, construímos o mundo, influenciados pelas ações, ideias, emoções e pelos pensamentos, sentimentos, valores e sonhos nossos e dos outros. Indica também que o conhecimento não é parte do sujeito e nem do objeto, senão da interação sujeito/ sujeito/objeto, (educador-educando), em que o sujeito que pratica a ação, sofre, simultaneamente, a ação do outro sujeito e/ou objeto. É a partir de ações ecologizadas, das interações ocorridas, que emergem novas estruturas e que possibilitam outras emergências e novas transcendências (Moraes e Torre, 2004). Deste modo, a educação e a sociedade se estabelecem e se enriquecem a partir das trocas entre sujeitos diversos. Portanto, a consciência dos valores se faz determinante para o ser e o fazer do professor. 


\section{O ser e o fazer do educador: novas miradas, novos caminhos, novos significados...}

Intuição, afetos, sonhos pensamos voam para além das disciplinas engaioladas, para além do pensar fragmentado. São saberes e sabores que trazem sentido à vida a partir de diferentes olhares... Destarte, ao professor-Educador cabe um olhar mais sensível, amoroso, compreensivo, mas não sem rigor e prudência...

"Se estamos preocupados em formar indivíduos autônomos, criativos, críticos, cooperativos, solidários e fraterno, mais integrados e harmoniosas, capazes de explorar o universo de suas construções intelectuais, teremos que optar por um novo tipo de paradigma educacional diferente dos modelos convencionais atuais e que, por sua vez, foram influenciados por determinadas correntes psicológicas e filosóficas ancoradas num determinado paradigma adotado pela ciência. '[...] para o desenvolvimento de um trabalho cooperativo, além de uma série de outros valores que necessitam ser resgatados nos novos ambientes de aprendizagem”. (Moraes, 2005, p.20).

Talvez possamos ver o anúncio de uma ciência com consciência (Morin, 2000a). Mas é preciso coerência, é preciso humildade, é preciso escolher com premência... Deste modo, discorramos sobre novos olhares que permeiam a práxis do Professor-Educador:

\section{Interdisciplinaridade: dando as mãos para refazer a tessitura da educação}

Muito mais que a comunicação, que a troca entre disciplinas é necessária a comunicação a troca entre saberes, caminhos, carinhos e sensibilização de pessoas. É necessária a espera do germinar da semente, é necessária a humildade diante do saber e do outro, é necessária a coerência do que sinto, penso e faço. É necessário o respeito por si mesmo e pelo outro e, é necessário o desapego aos nossos valores e pensamentos cristalizadores para que as portas de nossas gaiolas mentais se abram. Portanto, nos encontros partilhamentos e compartilhamentos, seguimos unindo-nos na e pela compreensão dos diferentes modos de ensinar e aprender, vinculando-os aos princípios interdisciplinares da espera, da humildade, da coerência, do respeito e do desapego (Fazenda, 2003).

É necessário desapego de nossos velhos pensamentos para nos libertarmos de nossas cegueiras, é necessária a espera e as humildade diante do tempo do outro; da novidade e assombro do diferente do que pensamos e do que pensa diferente de nós. É necessário coerência para que não percamos nosso caminho, ou senos perdermos, possamos colher saberes-flores e frutos daquilo que parecem espinhos. Porque o novo é estranho e diferente, assusta e assombra a gente, mas basta a amorosidade, o respeito, o dialogo e a abertura para se perceba um novo pensamento semente.

\section{Complexidade: a tessitura comum}

Complexo é aquilo que é tecido em conjunto, mas para melhor compreendermos a complexidade devemos entender melhor alguns princípios fundamentais implícitos nela. Estes princípios também nos servem como operadores dinâmicos no processo de construção do conhecimento, ou seja, operadores cognitivos. Para conhecermos estes princípios e operadores buscaremos os principais fundamentados no pensamento de Edgar Morin (2000b): 
- No princípio dialógico da complexidade percebemos que existem situações que não precisam se excluir ou deixar de existir. Elas existem e são necessárias. O preto não precisa deixar de ser preto para o branco existir. Preto e branco coexistem. Aquilo que parece antagônico é complementar.

É na busca do entrelaçar das relações e emoções que podemos vislumbrar o encontro de nossos valores essenciais, do nosso linguagear, do nosso emocionar para refazer a tessitura comum que nos liga a natureza, a sociedade e ao todo.

- Recursivamente, tudo que fazemos e pensamos, a nós retorna, mesmo que seja de uma maneira transformada. Os sujeitos fazem a cultura que novamente faz os sujeitos. Tudo que forma, transforma, este é um exemplo do princípio recursivo.

- todo é maior e menor que a soma das partes. O todo está nas partes e as partes estão no todo. Se apenas juntarmos as partes o todo se faz menor que a soma das partes. Se pensarmos no Todo como uma relação entre as partes (todos os aprendentes e ensinantes em relação) então podemos dizer que o todo é maior que as partes. Assim retomamos o sentido do sistêmico, da relação todo-parte. Poeticamente representando o pensar complexo: "vejo em ti o máximo do amor que há em mim e é através de ti que crio e recrio a mim mesma. Tu és meu espelho. O mundo é meu espelho e sou espelho do mundo". Este é o princípio hologramático da complexidade.

\section{O pensamento transdisciplinar: voando para além das gaiolas epistemológicas}

"Perceber a totalidade presente em cada momento da vida e os eixos por onde gravitam as tradições espirituais, a nova ciência, a arte e o saber do senso comum através de um olhar amoroso e criativo que busca re-significar a fala, a escuta, a relação do humano consigo mesmo, com o outro e com o ambiente que o cerca". (Walmir Cedotti, s/d)

Entre, através e além, é assim que se descreve a Transdisciplinaridade. Para além das disciplinas. É aqui que novamente se busca o sentido do saber e do ser. A Transdisciplinaridade também traz três princípios fundadores e fundamentais. São eles:

- Complexidade- a tessitura comum. Comungamos o mesmo universo e um mesmo planeta, o mesmo ar e a mesmas águas. Das relações cosmológicas as sinapses cerebrais tudo acontece em tessitura. Tudo esta ligado a tudo em algum nível e de alguma maneira.

- Existimos no nível de realidade macro físico (aquele que podemos ver); no nível microfísico, dos elétrons, prótons, bactérias etc. (aquele que não podemos ver) e ainda o nível virtual que nos cerca (o mundo onírico, o espaço do sagrado e a virtualidade do ciberespaço). Portanto, existimos em diferentes níveis de realidade.

- A lógica do terceiro incluído mostra que a tensão entre os contraditórios promove-se uma unidade que os inclui e vai além da soma dos dois termos. Esta lógica diz-nos que entre as extremidades de um bastão existe algo que os liga. Entre o erro e o acerto, em toda diversidade, existe um processo de aprendizagem. Aquilo que parece errado e estranho, é um espaço, um caminho de criação, muitas vezes de descoberta de novos saberes-fazeres. Erros e acertos coexistem. Entre o preto e o branco está algo invisível que os liga e dá sentido de serem preto e branco, ying e yang, 
É preciso chuva para florir, é preciso amor para abraçar, é preciso o abraço para o amor concretizar. A poésis, a intuição, a sensibilidade, a afetividade, o sagrado não tem fronteiras. São para além de gaiolas, são para além de disciplinas. Na Transdisciplinaridade poésis e ciência se abraçam e comungam a unidade na diversidade.

\section{Pensamento ecossistêmico: eu abraçado ao outro e ao Todo}

Escrevemos numa folha de papel e a folha de papel inscreve-se em nós. Porque, a árvore que é a folha que escrevemos, buscou no solo a seiva que também compõe a nós mesmos. Somos a folha de papel que escrevemos e nela está tudo de nós. Ao todo estamos ligados num imenso círculo ecossistêmico. Nutrimos o solo e pelo solo somos nutridos. Recursivamente construímos e reconstruímo-nos a cada palavra, gesto, símbolo.

Neste pensamento poético percebemos que transformamos a nós mesmos, ao outro e a natureza. Eu, o outro e a natureza nos transformamos sistemicamente. Assim, num imenso círculo recursivo e/ou retroativo, tudo que altera se altera. Quando tecemos a teia nos tecemos na Teia e a Teia da Vida (Capra, 1999) tece-se em nós e conosco.

Deste modo, é a partir das dificuldades, da desordem, do desequilíbrio, das dificuldades, da diversidade e das diferenças, aparentemente contraditórias, podem brotar conjunturas que instigam de maneira positiva a concepção e a renovação da prática educativa, do ser e fazerse Professor-Educador.

\section{Conclusões reflexivas}

Pensamos que, o Professor-Educador é aquele que acredita no que faz e o faz com amor, fundamento biológico da vida. Porque, por toda parte, no todo e na parte, abraçados -todo e parte-, o verbo se faz carne, a práxis se faz vida, o ser e o fazer tornam-se unos na tessitura da lida e da vida.

Deste modo, chamamos os educadores à reflexão, para que a educação sirva-nos não somente para ampliar nosso potencial de aprendências sobre coisas do mundo, mas de perceber os valores aos quais essas coisas estão ligadas, para que não percamos o desejo de ampliar o que aprendemos. E, sobretudo, que nos possibilite o ampliar da capacidade de extrair o significado das experiências e seguirmos no tear de um trabalho de criação partilhada e amorosamente plena de saberes, no qual os diferentes aprendentes se sintam motivados a sentipensar, amar, a conviver-e-saber.

Refletir para que a educação seja a arte de formar, ou melhor, de transformar, de acordar para o seu mundo vida para que tragam vida para o mundo. Que o "fazer" não tenha mais valor que o "Ser", mas que juntos sejam coadjuvantes no semear de sonhos e o desabrochar de autorias.

Para que a educação democrática se concretize, é necessário que saibamos quais sujeitos queremos formar, conscientes da coerência do "porque formar" e "para que formar". Porquanto, é neste "para quê formar" que está nossa ação valorativa, libertadora, da ação amorosa e acolhedora para conosco, com os educandos e para o mundo. Assim, a educação seguirá a incansável busca pela da liberdade, democracia, igualdade social, fraternidade. Esta luta da construção do humano do humano, da coragem serena, de sabedoria e humilde do voar com o outro, do religar a Teia da Vida.

Assim, devemos seguir buscando: 
“[...] um mundo menos terrível, menos cruel, podemos esperar uma humanização, podemos humanizar e civilizar nossa Terra. Tudo isso pressupõe, ainda, a religação. Ela é uma necessidade vital para o pensamento, para o desabrochar dos seres humanos, que precisam de amizade e de amor e que, sem isso, definham e se amarguram". (Morin, 2002, p. 53)

Na partitura da vida, a sinfonia não tem início nem partida. Todos somos maestros, tocamos nossos instrumentos e, com nossos sons, em alguns arranjos harmônicos criados por nossas diferenças, tocamos canções novas que dão sentido as nossas existências. 


\section{Referencias}

Alves, M. D. F.; (2011). cap. 8. "Bullying- sintoma de uma necrose dos des-envolvimento. Reencantando os valores na rua, na lua, na família e na nação". In Valle, L. E. L R. e Mattos, M. J. V. M. (orgs.). Violência e educação. A sociedade criando alternativas, pp. 166-188. Rio de Janeiro: WAK.

- (2009a). De professor a educador. Contribuições da Psicopedagogia: ressignificar os valores e despertar a autoria. $2^{\mathrm{a}}$. Ed. Rio de Janeiro: WAK Editora.

- (2009b). Favorecendo a Inclusão pelos caminhos do coração: complexidade, pensamento ecosistêmico e Transdisciplinaridade. Rio de Janeiro, WAK.

Assmann, H. (1998.). Reencantar a educação: rumo à sociedade aprendente. Petrópolis, R.J.: vozes. Bauman, Z. (2001). Modernidade Líquida. Rio de Janeiro: Jorge Zahar.

Boff, L. (1999). Ética da Vida. Brasília: Letraviva.

Capra, F. (1999). A teia da vida: uma compreensão científica dos sistemas vivos. São Paulo: Primeira edição.

D’Ambrosio, U. (1997). A era da consciência. São Paulo: Peirópolis.

Delors, J. (2000). Educação, um tesouro a descobrir. São Paulo: Cortez.

FAZENDA, I. C. A. (2003). Interdisciplinaridade: Qual o sentido? São Paulo: Paulus.

Feldmann, M. G. (org.). (2009). Formação de professores e escola na contemporaneidade. São Paulo: Editora Senac.

Freire, P. (2001). A pedagogia da autonomia. Paz e Terra.

-. (1985). A pedagogia do Oprimido. 17 ed. Rio de Janeiro, Paz e Terra.

Maturana, H. (1997). Ontologia da realidade. Belo Horizonte: Ed. UFMG.

-; Verden-Zoller, Gerda. (2004). Amar e Brincar: fundamentos esquecidos do humano. São Paulo: Palas Athena.

—; Rezepka, S.. N. de. (2000). Formação humana e capacitação. Petrópolis: Vozes.

-; Varela, F. (1995). A árvore do conhecimento: as bases biológicas do entendimento humano. São Paulo: Psy.

Moraes, M. C. (2008). Ecologia dos saberes: Transdisciplinaridade, complexidade e educação. São Paulo: ProLíbera Editora: Antakarana/WHH -Willis Harman House.

-. (2005). O paradigma educacional emergente. Campinas/SP: Papirus

—. (2004). Pensamento Eco-sistêmico: educação, aprendizagem e cidadania no século XXI. $8^{\mathrm{a}}$ Ed. São Paulo: Vozes.

-. (2003). Educar na Biologia do Amor e da Solidariedade. São Paulo: Vozes.

-; Torre, S. de la. (2004). Sentipensar: fundamentos e estratégias para reencantar a Educação. Vozes. Morin, E. (2000a). Ciência com consciência . 4. ed. Rio de Janeiro: Bertrand Brasil.

- (2000b). A inteligência da complexidade. 3. ed. São Paulo: Peirópolis.

- (2002). O método V. A humanidade da humanidade: a identidade e humanas. Porto Alegre: Sulina.

- (1996.). Os sete saberes necessários para a educação do futuro. São Paulo: Cortez

Nicolescu, B. (1999). O manifesto da transdisciplinaridade. São Paulo: Triom.

Santos, B. de S. (1996). Um discurso sobre as ciências. 8 ed., Porto: Afrontamento.

Steiner, R.. L. (1998). A Pedagogia Waldorf - Caminho para um Ensino mais Humano. 6 ed. São Paulo: Ed. Antroposófica.

Tardif, M.; Lessard, C. (2005). O trabalho docente: elementos para uma teoria da docência como profissão de interações humanas. 2.ed. Petrópolis: Vozes. 


\section{Sobre la Autora}

Dra. Maria Dolores Fortes Alves: Doutoranda (CNPq) e Mestre em Educação pela PUC/SP; Mestre em Psicopedagogia-UNISA; Pós-Graduada em Distúrbios da Aprendizagem - UBA (Universidade de Buenos Aires); Especialista em Educação em Valores Humanos; PedagogaUNISA; Pesquisadora do GEPI (Grupo de Estudos Pesquisas Interdisciplinares) RIES (Rede Internacional Ecologia dos Saberes) e, ECOTRANSD (Ecologia dos Saberes e Transdisciplinaridade); Docente de Pós-Graduação. Assessora Educacional; Palestrante, Conferencista. Autora de diversos artigos e livros. 